\title{
The Cycle of Violence: Associations Between Exposure to Violence, Trauma-Related Symptoms and Aggression-Findings from Congolese Refugees in Uganda
}

\author{
Tobias Hecker, ${ }^{1,2,4}$ Simon Fetz, ${ }^{2}$ Herbert Ainamani, ${ }^{3}$ and Thomas Elbert $2,3,4$ \\ ${ }^{1}$ Department of Psychology, University of Zurich, Zurich, Switzerland \\ ${ }^{2}$ Department of Psychology, University of Konstanz, Konstanz, Germany \\ ${ }^{3}$ Department of Psychology, Mbarara University of Science and Technology, Mbarara, Uganda \\ ${ }^{4}$ vivo international, www.vivo.org
}

\begin{abstract}
War-related trauma exposure has been linked to aggression and enhanced levels of community and family violence, suggesting a cycle of violence. Reactive aggression — an aggressive reaction to a perceived threat - has been associated with posttraumatic stress disorder (PTSD). In contrast, appetitive aggression—a hedonic, intrinsically motivated form of aggression—seems to be negatively related to PTSD in offender and military populations. This study examined the associations between exposure to violence, trauma-related symptoms and aggression in a civilian population. In semistructured interviews, 290 Congolese refugees were questioned about trauma exposure, PTSD symptoms, and aggression. War-related trauma exposure correlated positively with exposure to family and community violence in the past month $(r=.31, p<.001)$, and appetitive $(r=.18, p=.002)$ and reactive aggression $(r=.29, p<.001)$. The relationship between war-related trauma exposure and reactive aggressive behavior was mediated by PTSD symptoms and appetitive aggression. In a multiple sequential regression analysis, trauma exposure $(\beta=.43, p<.001)$ and reactive aggression $(\beta=.36, p<.001)$ were positively associated with PTSD symptoms, whereas appetitive aggression was negatively associated $(\beta=-.13, p=.007)$ with PTSD symptoms. Our findings were congruent with the cycle of violence hypothesis and indicate a differential relation between distinct subtypes of aggression and PTSD.
\end{abstract}

Forced migration is one of the major challenges for the international community. Recently, the United Nations High Commissioner for Refugees (UNHCR) announced a major increase in worldwide refugee numbers that has not been seen since the early 1990s (UNHCR, 2013a). In the middle of 2013, 490,000 persons originating from the Democratic Republic of Congo (DRC) were forced to seek refuge in neighboring countries, many of them in Uganda (UNHCR, 2013b). The DRC has been trapped in an ongoing cycle of war and violence for more than two decades. Civilians suffer on a large scale from the consequences of violence (Elbert et al., 2013). With the

This research was supported by the Deutsche Forschungsgemeinschaft and by the NGO vivo international. We are grateful to all of the refugees who participated in this study for their readiness to participate and willingness to discuss often intimate and painful subjects. We are very grateful to our highly motivated and reliable research team, including Djuna Kashira, Dickson Kambere, and Dina Nirere. We also thank James Moran who critically reviewed the manuscript.

Correspondence concerning this article should be addressed to Tobias Hecker, Department of Psychology, University of Zurich, Binzmuehlestr. 14/17, 8050 Zurich, Switzerland. E-mail: t.hecker@psychologie.uzh.ch

Copyright $\odot 2015$ Wiley Periodicals, Inc., A Wiley Company. View this article online at wileyonlinelibrary.com

DOI: $10.1002 /$ jts. 22046 rise of the insurgency Mouvement du 23 mars in early 2012, the eastern DRC entered another period of high conflict intensity, which peaked when they took over the regional capital of Goma.

Violence and forced migration have a number of significant consequences. Besides facing precarious economic situations, sorrow over losses, and threats to physical integrity, refugees often suffer from trauma-related disorders like posttraumatic stress disorder (PTSD), major depression, and substance abuse (Fazel, Wheeler, \& Danesh, 2005; Leeies, Pagura, Sareen, \& Bolton, 2010). It has been repeatedly reported that the number of potentially traumatizing event types a person is exposed to is positively associated with the development of PTSD symptoms (Hermenau et al., 2011; Kolassa et al., 2010; Schauer et al., 2003). This effect of cumulative exposure to traumatic stress has been termed the "building block effect" (Neuner, Schauer, Karunakara, et al., 2004). Beyond PTSD symptoms, survivors of trauma often face difficulties in rebuilding their lives even if after taking refuge they reach an environment that is relatively safer than the war at their home. Thus, the consequences of high PTSD prevalence in a population of refugees may go beyond individual suffering and impact the livelihoods of family members and whole communities (Neuner, Schauer, Klaschik, Karunakara, \& Elbert, 2004). 
It is, therefore, not surprising that elevated levels of community and family violence have been reported in postwar communities. These were highly correlated with war-related trauma exposure (Catani, Jacob, Schauer, Kohila, \& Neuner, 2008). Other studies reported a positive relation between war-related PTSD symptom severity and aggressive behavior (Saile, Ertl, Neuner, \& Catani, 2014). For example, high PTSD symptom severity was associated with reactive aggression-an aggressive reaction to some perceived provocation or threat-in survivors of hurricane Katrina (Marsee, 2008) and veterans (Byrne \& Riggs, 1996). When a person experiences repeated and constant threats to his or her life, this person may develop cognitive networks that guide cognitions, emotions, and actions to increase chances of survival (Elbert \& Schauer, 2002). Although being highly alert and aroused in dangerous situations has survival advantages, in situations where threat to life is low, such as in refugee settlements, it can produce inappropriate and aggressive behavior. Correspondingly, child soldiers who have been frequently exposed to severe violence perpetrated more types of violence (Weierstall, Schalinski, Crombach, Hecker, \& Elbert, 2012). Furthermore, it has been repeatedly shown that a person's own experiences of childhood maltreatment and their own victimization through intimate partner violence predict aggressive parenting behavior (Conger, Place, \& Neppl, 2012; Saile et al., 2014; Thornberry, Knight, \& Lovegrove, 2012). These findings provide further evidence that exposure to violence in the past is associated with the display of aggressive behavior and violence today. Following this cycle of violence hypothesis, we can predict that high levels of exposure to war-related violence may lead to higher levels of aggressive behavior (Elbert, Rockstroh, Kolassa, Schauer, \& Neuner, 2006).

The findings of Weierstall et al., (2012), however, were not limited simply to reactively aggressive acts that grew out of trauma-related suffering. Instead, they reported that exposure to violence fostered appetitive aggression. For this subtype of aggression, the infliction of harm upon an individual is itself rewarding, fascinating, and a source of enjoyment — above and beyond secondary rewards like status or material benefits (Elbert, Weierstall, \& Schauer, 2010; Hecker, Hermenau, Maedl, Elbert, \& Schauer, 2012). In environments dominated by war and organized violence, exposure to violence and other traumatic stressors have been linked to appetitive aggression (Weierstall, Bueno Castellanos, Neuner, \& Elbert, 2013) and encouraged violent behavior, thereby creating a cycle of violence (Hecker, Hermenau, Maedl, Hinkel, Schauer \& Elbert, 2013). Developing appetitive aggression seems to be an adaptive survival strategy for children growing up in a violent environment (Hermenau, Hecker, Maedl, Schauer, \& Elbert, 2013). Elbert et al. (2010) argue that in analogy to the fear network in PTSD, a hunting network may be formed, marked by approach rather than avoidance to violence cues. Experiences of highly arousing events are stored in propositional networks that are configured by new learning experiences. The representation of memory in associative networks is a consequence of Hebb's rule (1949; $p$. 60 ) according to which a given link will be strengthened (either by an increase of excitatory gain, or by a decrease of inhibitory gain) if the two units that it connects are active simultaneously. When exposed to a combat event, sensory and perceptual information (e.g., the sound of cries and victory) together with the cognitive (e.g., the thought "I will be the hero"), affective (e.g., feelings of excitement), and physiological responses (e.g., increase in heart rate) is stored in memory. When recalled, mind and body become aroused and are braced for actions such as fighting or killing. When this network becomes tied to positive valence cues, we call it a hunting network. It is obvious that many of these elements may also be connected to negative valence and form the so-called fear network instead. The valence and with it, the prominent response-approach or avoidancesegregates these two networks (Hecker, Hermenau, Crombach, \& Elbert, 2015). Correspondingly, brain response patterns differ for these two networks even when activated by script-driven imagery (Moran, Weierstall, \& Elbert, 2014). This network model corresponds well with results of structural and functional alterations in the brain of trauma survivors with PTSD (Kolassa \& Elbert, 2007; Kolassa, Illek, Wilker, Karabatsiakis, \& Elbert, 2015).

Because the appetitive, fascinating element of violence seems to prevent the incorporation of the cruel, genuinely traumatizing experiences into the fear network, appetitive-aggressive individuals may have a higher chance of survival in a violent environment. Thus, the possibility that appetitive aggression may promote resilience against PTSD can be explained based on the competition between the networks representing the generalized fear and hunting experiences. Accordingly, recent studies reported a negative association between appetitive aggression and PTSD symptom severity in military populations and violent offenders, such as members of armed groups (Hecker, Hermenau, Maedl, Schauer, \& Elbert, 2013), former child soldiers (Weierstall et al., 2012), genocide perpetrators (Weierstall, Schaal, Schalinski, Dusingizemungu, \& Elbert, 2011), and violent youths (Weierstall et al., 2013), indicating that individuals with high levels of appetitive aggression were less likely to report PTSD symptoms. All studies thus far, however, investigating this relation have focused exclusively on military populations and violent offenders. Yet, little is known about this relationship in civilian populations.

The aim of the present study was to examine the associations between exposure to violence, trauma-related symptoms, and distinct subtypes of aggression in a civilian population of refugees from a region of ongoing war and conflict. Following the cycle of violence hypothesis, we hypothesized that (a) war-related trauma exposure would be correlated with current exposure to community and family violence, and (b) that exposure to both war-related and community and family violence would be linked to appetitive and reactive aggression. Furthermore, we hypothesized that (c) both trauma exposure and reactive aggression would be associated positively with PTSD symptom severity, whereas (d) appetitive aggression would be associated negatively with PTSD symptom severity. 
Table 1

Descriptive Statistics

\begin{tabular}{|c|c|c|c|c|c|}
\hline \multirow[b]{2}{*}{ Variable } & \multicolumn{2}{|c|}{ Male $(n=121)$} & \multicolumn{3}{|c|}{ Female $(n=169)$} \\
\hline & $M$ & $S D$ & $M$ & $S D$ & $t$ \\
\hline Age (years) & 31.97 & 9.04 & 30.79 & 9.19 & 1.09 \\
\hline PTSD symptom severity & 28.67 & 14.35 & 35.31 & 11.80 & $4.18 * * *$ \\
\hline Appetitive aggression & 4.79 & 4.45 & 4.78 & 4.78 & 0.03 \\
\hline Reactive aggression & 21.72 & 11.29 & 24.61 & 10.62 & $2.12 *$ \\
\hline Trauma exposure & 33.64 & 7.29 & 35.66 & 7.98 & $2.17 *$ \\
\hline War-related & 18.07 & 3.59 & 18.67 & 3.96 & 1.33 \\
\hline Family \& community violence ${ }^{a}$ & 2.82 & 2.32 & 3.31 & 3.03 & 1.56 \\
\hline
\end{tabular}

Note. $t=t$ test or Welch-test statistics; PTSD $=$ posttraumatic stress disorder.

${ }^{a}$ Experienced in the past 4 weeks.

${ }^{*} p \leq .05 . * * p \leq .01 . * * * p \leq .001$

\section{Method}

\section{Participants and Procedure}

Between March and June 2013 a sample of 329 persons were interviewed in Nakivale Refugee Settlement in Western Uganda. Since the beginning of 2012, this settlement has received a high influx of refugees from the DRC. In March 2014 the population of the settlement was 60,992 persons, of whom 32,455 were Congolese (UNHCR Uganda, 2015). Only refugees from Eastern DRC who had arrived in the settlement after January 2012 were interviewed. This inclusion criterion was validated at the beginning of each interview. In the present study, we included only civilians $(N=290)$ and excluded those interviewees who had reported that they had been a soldier, a combatant, or that they had fought in combat themselves. Of the included sample, $58.3 \%(n=169)$ were women. The mean age was 31.28 years $(S D=9.13$, range $=18-65)$. All of them reported having fled from Eastern DRC because of the threats they were facing due to the conflict in their home country. Table 1 displays the descriptive statistics.

Three psychologists (T.H., F.S., H.A.) and a local social scientist from the Congolese refugee community conducted the semistructured interviews. All interviewers were extensively trained in psychological assessment. All interviews were conducted in Swahili, which is the lingua franca both in the Eastern DRC and in Nakivale refugee camp. The interviewers practiced the assessment in joint interviews to accomplish high interrater reliability (not assessed). Two English-speaking interpreters facilitated communication.

The Mbarara University of Science and Technology Institutional Review Board as well as the Ugandan National Council for Science and Technology approved this study. The interviews took place in different parts of the refugee settlement. We first contacted the local authorities of the settlement's subdivisions. After giving their consent, the authorities announced our arrival in their communities and gathered suitable persons. Using snowball sampling we returned to the respective places until no more persons fulfilling the inclusion criteria appeared. After that, we went on to the next subdivision where recent arrivals were living. We collected oral and written informed consent from the participants to ensure comprehension and full awareness of the content; illiterate participants gave their fingerprints instead of a signature. Each interviewee was interviewed in a calm and discreet setting. At the end of the interview, each participant received a bar of soap and a package of salt as compensation.

\section{Measures}

All assessment instruments were completed as semistructured interviews including sociodemographic information (e.g., age, sex).

Lifetime exposure to traumatizing events was assessed using a checklist of 30 war- and nonwar-event types (e.g. natural catastrophes, physical assault, sexual assault). This checklist was an adapted version of a checklist by Neuner, Schauer, Karunakara, et al. (2004), which had previously shown high test-retest reliability and statistically significant accordance with the event list of the Composite International Diagnostic Interview in a study in Uganda (Ertl et al., 2010). It has also been successfully used in studies in the DRC (e.g., Hermenau, Hecker, Schaal, et al., 2013). The number of times a specific event had been experienced was not assessed; measuring event types provides an accurate and practical measure of trauma experiences (Wilker et al., 2015). Furthermore, we assessed current exposure to community and family violence with 20 violence-related events (e.g., physical assault, sexual assault); each item inquiring about lifetime exposure and pastmonth exposure. For the analysis, we calculated a sum score of lifetime trauma exposure by summing all items (range $=0-51$ ). We further calculated scores for war-related trauma exposure (range $=0-24$ ) and current exposure to community and family violence $($ range $=0-20)$. 
The PTSD Symptom Scale-Interview (PSS-I; Foa, Riggs, Dancu, \& Rothbaum, 1993) was utilized to determine PTSD symptom severity. The 17 symptom criteria for PTSD according to the Diagnostic and Statistical Manual of Mental Disorders (4th ed., DSM-IV; American Psychiatric Association, 1994) were assessed with one question for each symptom and referred to the previous 2 weeks. The answers were coded on a 4-point scale ranging from $0=$ not at all to $3=$ five or more times per week/very much. The PSS-I has been shown to have good psychometric properties (e.g. Cronbach's $\alpha=.86$, interrater reliability $=.93$; Foa $\&$ Tolin, 2000). The instrument has been validated for use in Uganda (Ertl et al., 2010) and has been successfully used in the DRC (e.g., Hecker, Hermenau, Maedl, Hinkel, et al., 2013; Schalinski, Elbert, \& Schauer, 2011). We computed dimensional PTSD severity scores as the sum ranged from 0 to 51. Cronbach's $\alpha$ coefficient in present sample was 96.

For the assessment of two distinct forms of current aggressive behavior-appetitive and reactive aggression - we used the Appetitive and Facilitative Aggression Scale (AFAS), a two-dimensional scale consisting of 30 items, 15 for each form of aggression. The 15 questions regarding reactive aggression concern situations in which aggressive behavior has the aim of resolving a highly arousing and aversive state (Weierstall \& Elbert, 2012): for example, "When you were enraged with someone, did you fantasize about terrible things happening to them?," and "Did you hit out in anger, when somebody provoked you?" The items for reactive aggression were formulated based on the circumplex model of affect by Russell (1980), whereby physical pain as well as social exclusion were integrated as potential stressors (e.g., MacDonald \& Leary, 2005). In contrast, the 15 questions regarding appetitive aggression ask for situations in which aggressive behavior had the aim of reaching a positive and high arousing state: for example, "Was it fun for you to fight?," and "When you attacked someone, did you feel strong?" The subscale for appetitive aggression was an adapted version of the Appetitive Aggression Scale (AAS; Weierstall \& Elbert, 2011) for civil populations. The AAS has been validated in similar settings, including within Uganda (Weierstall et al., 2012) and the DRC (Hecker et al., 2012). The items for appetitive aggression were based on the definition of the instrumental aggression subtype according to Vitiello and Stoff (1997) and the ICD-10 addiction criteria (World Health Organization, 1992). The interviewer rated how frequently each participant had shown the corresponding behavior over the past 4 weeks on a 5-point Likert scale ranging from $0=$ never to $4=$ very often/more than two times per week. The AFAS was carefully translated into Swahili. A blind back-translation was conducted. Discrepancies between the original and back-translation were identified and resolved. For the analysis we created two scores, one for each distinct form of aggression, each ranging from 0 to 60 . Cronbach's $\alpha$ coefficient for this sample was .78 for the reactive aggression subscale and .90 for the appetitive aggression subscale.

\section{Data Analysis}

To test the cycle of violence hypothesis we used Pearson's correlation coefficient. Using a path model we explored the potential mediating influence of PTSD symptom severity and appetitive aggression on the relation between war-related trauma exposure and reactive aggression applying maximum likelihood method of estimation; in case of missing data means and intercepts were estimated (Schumacker \& Lomax, 2010). Goodness of fit was assessed using the following indices: $\chi^{2}$; confirmatory fit index (CFI), with values greater than .95 indicating good fit; and root mean square error of approximation (RMSEA), with values less than .05 indicating close fit (Hu \& Bentler, 1999). The significance test for close fit is akin to that of the $\chi^{2}: p<.05$ signifies that the hypothesis of close fit is rejected. Akaike information criterion (AIC) is a comparative measure of fit. Lower values indicate better fit. Preliminary analyses confirmed that all statistical assumptions (normality, linearity, collinearity, reliability, and missing value analysis) for using path models were met. Neither univariate nor multivariate outliers could be detected. Our metric for a small effect size was $\beta \geq .10$, for a medium effect $\beta \geq .30$, and for a large effect $\beta \geq .50$.

Using a sequential multiple regression, we regressed the PTSD symptom severity on lifetime trauma exposure, appetitive aggression and reactive aggression scores. In the first step, we entered age and sex (male $=0$; female $=1)$ as potential confounding variables (based on prior research findings and a positive correlation with PTSD symptom severity). Then, we entered the lifetime trauma exposure score, and in the third step we entered the two aggression scores. Five subjects were excluded due to missing data. All necessary quality criteria for a multiple linear regression were fulfilled. The residuals did not deviate significantly from normality (Kolmogorow-Smirnov- $Z$ $=0.58, p=.895$ ), linearity, or homoscedasticity. No univariate outliers could be identified. Mahalanobis' distance revealed one multivariate outlier (Mahalanobi's $D>20.59$; Stevens, 1984), which was excluded from the analysis. Variance inflation factor did not exceed 1.25 , thus we did not need to take multicollinearity into account. Our metric for a small effect size was $f^{2} \geq$ .02 , for a medium effect, $f^{2} \geq .15$; and for a large effect, $f^{2} \geq$ .35. All analyses used a two-tailed $\alpha=.05$. Data were analyzed with IBM SPSS Statistics 21 and IBM SPSS Amos 21.

\section{Results}

We found that the war-related trauma exposure was positively correlated with current exposure to community and family violence $(r=.31, p<.001)$, appetitive aggression $(r=.18$, $p=.002)$, and reactive aggression $(r=.29, p<.001)$. Current exposure to community and family violence correlated positively with appetitive aggression $(r=.27, p<.001)$ and reactive aggression $(r=.16, p=.006)$. In the best-fitting path model, PTSD symptom severity and appetitive aggression fully mediated the relation between war-related trauma exposure and reactive aggression (Table 2, Figure 1). The potentially 
Table 2

Maximum Likelihood Estimates of the Path of PTSD Symptom Severity

\begin{tabular}{lrrrc}
\hline & $B$ & $S E$ & $\beta$ & $C R$ \\
\hline Variable & & & & \\
Sex & 5.17 & 1.25 & .20 & $4.15^{* * *}$ \\
Age (years) & -0.19 & 0.07 & -.13 & $-2.75^{* *}$ \\
War-related trauma exposure & 1.89 & 0.16 & .55 & $11.74 * * *$ \\
$\quad \begin{array}{l}\text { Appetitive aggression } \\
\quad \text { War-related trauma exposure }\end{array}$ & 0.22 & 0.07 & .19 & $3.21 * * *$ \\
$\quad$ Reactive aggression & & & & \\
$\quad$ War-related trauma exposure & -0.09 & 0.18 & -.03 & -0.51 \\
$\quad$ PTSD symptom severity & 0.43 & 0.05 & .50 & $8.51 * * *$ \\
$\quad$ Appetitive aggression & 0.54 & 0.12 & .22 & $4.38 * * *$ \\
\hline
\end{tabular}

Note. $N=290 . C R=$ critical ratio; $\mathrm{PTSD}=$ posttraumatic stress disorder. $* p \leq .05 . * * p \leq .01 . * * * p \leq .001$

confounding variables, age and sex were significantly correlated with PTSD symptom severity, but not with reactive aggression. The results of the path model indicated good model fit, $\chi^{2}(8, n=290)=7.38, p=.50 ;$ RMSEA $<.001,90 \%$ confidence interval (CI) $[.000, .065]$, PClose $=.856 ; \mathrm{CFI}>$ 0.99; $\mathrm{AIC}=45.38$. Other models, including current exposure to community and family violence $(\mathrm{AIC}=46.64)$ or sex and age $(\mathrm{AIC}=49.34)$ as predictors of reactive aggression, showed worse model fit.

The regression model containing only sex and age explained $7.3 \%$ of the variability of the PTSD symptom severity, $R_{\mathrm{adj}}{ }^{2}=$ $.07, F(2,282)=12.23, p<.001, f^{2}=.08$. Adding the lifetime trauma exposure score improved the model significantly,

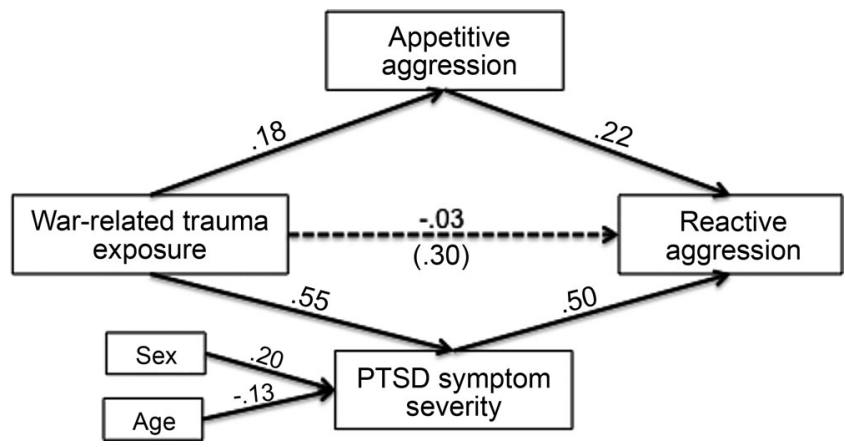

Figure 1. Path model $(N=290)$ exploring the mediating influence of posttraumatic stress disorder (PTSD) severity and appetitive aggression on the relation between war-related trauma exposure and reactive aggression. This model is consistent with the view that the relation between war-related trauma exposure and current reactive aggressive behavior is fully mediated by severity of PTSD symptoms and appetitive aggression: The relation between war-related trauma exposure and reactive aggression was significant $(\beta=.30)$. This significant relationship disappeared when including appetitive aggression and PTSD symptom severity as mediators to the model $(\beta=-.03)$. Standardized regression weights are depicted; all continuous lines are significant beyond .05 , the dashed line indicates that the relationship is not significant. Error variables are omitted for clarity.
Table 3

Multiple Regression Analysis of PTSD Symptom Severity

\begin{tabular}{lrrrc}
\hline Variable & $B$ & $S E$ & $\beta$ & $t$ \\
\hline Step 1 & & & & \\
$\quad$ Sex & 6.17 & 1.54 & .23 & $4.02^{* * *}$ \\
Age (years) & -0.22 & 0.83 & -.15 & $-3.66^{*}$ \\
Step 2 & & & & \\
Sex & 4.54 & 1.31 & .17 & $3.46^{* * *}$ \\
Age (years) & -0.14 & 0.07 & -.10 & $-1.97^{*}$ \\
Trauma exposure & 0.88 & 0.08 & .53 & $10.52^{* * *}$ \\
Step 3 & & & & \\
Sex & 3.70 & 1.21 & .14 & $3.06 * *$ \\
Age (years) & -0.12 & 0.07 & -.08 & -1.84 \\
Traumatic exposure & 0.74 & 0.09 & .43 & $8.68^{* * *}$ \\
Appetitive aggression & -0.40 & 0.15 & -.13 & $-2.73^{* *}$ \\
Reactive aggression & 0.42 & 0.06 & .36 & $7.26^{* * *}$ \\
\hline
\end{tabular}

Note. $R^{2} \mathrm{adj}=.44, f^{2}=.79, n=285 . \mathrm{PTSD}=$ posttraumatic stress disorder. $* p \leq .05 . * * p \leq .01 . * * * p \leq .001$.

$\Delta R^{2}=0.26, F(1,281)=110.76, p<.001, f^{2}=.35$. This updated model explained $33.3 \%$ of the variance. After adding appetitive aggression and reactive aggression, the improvement of the model was significant, $\Delta R^{2}=.11, F(2,279)=27.29$, $p<.001, f^{2}=.12$; this model explained $43.8 \%$ of the variance. Two-way interactions did not further improve the model. Both lifetime trauma exposure and reactive aggression correlated positively with PTSD symptom severity, whereas appetitive aggression correlated negatively with PTSD symptom severity (Table 3).

\section{Discussion}

The aim of the present study was to examine the associations between exposure to violence, trauma-related symptoms, and distinct subtypes of aggression in a civilian population of refugees from a region of ongoing war and conflict. In agreement with our hypothesis, we found a positive correlation between warrelated trauma exposure and current exposure to community and family violence. This was in accord with prior findings showing a positive association between exposure to violence in war and conflict with family and community violence (Catani et al., 2008). The path model indicated that the relation between war-related trauma exposure and current (reactive) aggressive behavior was mediated by PTSD symptom severity and appetitive aggression. Our results suggested that elevated levels of aggressive behavior and violence in refugee communities and postwar societies may be explained by trauma-related symptoms and appetitive aggression, both potential consequences of war-related trauma exposure. In concordance with prior research (Saile et al., 2014), we found that exposure to violence (in war, community, and family) was related to current aggressive behavior. Our findings were congruent with the cycle 
of violence hypothesis that violence breeds further violence (Elbert et al., 2006; Saile et al., 2014).

In accord with prior studies (Marsee, 2008), we found a positive association between PTSD symptom severity and reactive aggression. Our study design, however, did not allow any conclusions about whether reactive aggression was a symptom of PTSD or whether aggressive behavior constitutes a risk factor for developing trauma-related disorders. Future research is needed to take a closer look at the development of reactive aggression and its causal relation to PTSD.

Appetitive aggression was, however, negatively correlated with PTSD symptom severity. In other words, the more fascinating and rewarding violence in itself is perceived, the lower the level of reported PTSD symptoms may be. This negative relationship has already been shown in several military populations and violent offenders (Hecker, Hermenau, Maedl, Schauer, et al., 2013; Weierstall et al., 2011; Weierstall, Hinsberger, et al., 2013). The present study found this negative relation for the first time in a civilian population of refugees. In a violent environment, appetitive aggression may be an adaptation to a situation of constant threat (Hermenau, Hecker, Maedl, et al., 2013). Elbert et al. (2010) argue that the appetitive and fascinating element of violence prevents the incorporation of the cruel, genuinely traumatizing experiences into the fear network. Therefore, we argue that refugees who perceive witnessing violence and one's own aggressive behavior to be fascinating and arousing are more likely to integrate violence-related behavior, sensory input, cognitions, and emotions into the hunting network. The level of reported appetitive aggression varies greatly between studies. Prior studies targeting military and offender populations revealed much higher levels of appetitive aggression, with mean scores ranging from 15 to 28 (e.g. Hecker et al., 2013; Weierstall et al., 2011). Yet, this lower level in a civilian sample is not surprising as prior research repeatedly indicated that the perpetration of violence was the strongest correlate of appetitive aggression (Hecker et al., 2012; Weierstall et al., 2012). Nonetheless, we found this negative relation between appetitive aggression and PTSD symptom severity in the present study. Further research is needed to replicate our findings in other civilian populations.

In regions of ongoing conflict it is important to be aware of the fact that aggressive behavior in conflict settings might be a consequence of experienced atrocities. Frequent and severe exposure to violence may not only heighten the risk of acting aggressively, but also seems to affect attitudes towards violence and aggression, such that it becomes perceived as appetitive. The combination of trauma-related symptoms (PTSD, depression, alcohol abuse) and enhanced level of appetitive aggression may partially explain the relation between war-related trauma exposure and high levels of community violence (Saile et al., 2014). Future studies should explore this potentially mediating influence more closely. Our findings underline the need for mental health policies and services to be aware of elevated levels of aggression in the aftermath of war and conflict as they potentially contribute to increased family and community violence.
There were some limitations of the study that should be noted. First, the cross-sectional study design did not allow for the establishment of directionality. Therefore, the reported relations need to be interpreted with caution. For example, it cannot be determined whether reactive aggression was a symptom of PTSD or if it constituted a potential risk factor. Also it remains unclear whether the negative relation between appetitive aggression and PTSD symptom severity constitutes a protective influence against the development of PTSD symptoms or whether participants suffering from PTSD perceive violence as less arousing and fascinating. Longitudinal and prospective studies are needed to shed light on the causal relations. The present convenience sample may have resulted in a selection bias, which limits the generalizability of our findings. Generally, the participants talked very openly about their experiences and feelings. Potential biases, however, such as social desirability, can never be ruled out for subjective reports. Moreover, associative memory networks such as the hunting network are theoretical concepts based on Hebbian learning. Further empirical support from experimental design is needed to specify the underlying mechanisms of our findings.

The present study was congruent with the notion that in the context of war and conflict, a cycle of violence persists, which links exposure to organized, community, and family violence with aggressive behavior. Thus, our findings may help to understand the high levels of community and family violence in refugee settlements as well as in postwar societies. Our findings, furthermore, indicate the differential relation between distinct subtypes of aggression and PTSD symptom severity: PTSD symptom severity was positively related to reactive aggression, and negatively related to appetitive aggression. Our study is the first of which we are aware to demonstrate this negative association in a civilian population. It seems important for mental health policies and services to consider elevated levels of aggression in the aftermath of war and conflict.

\section{References}

American Psychiatric Association. (1994). Diagnostic and statistical manual of mental disorders ( $4^{\text {th }}$ ed.). Washington, DC: Author.

Byrne, C. A., \& Riggs, D. S. (1996). The cycle of trauma: Relationship aggression in male Vietnam veterans with symptoms of posttraumatic stress disorder. Violence and Victims, 11, 213-225.

Catani, C., Jacob, N., Schauer, E., Kohila, M., \& Neuner, F. (2008). Family violence, war, and natural disasters: A study of the effect of extreme stress on children's mental health in Sri Lanka. BMC Psychiatry, 8, 33. doi:10.1186/1471-244X-8-33

Conger, R. D., Place, C., \& Neppl, T. K. (2012). Intergenerational continuity and discontinuity in harsh parenting. Parenting: Science and Practice, 12, 222-231. doi:10.1080/15295192.2012.683360

Elbert, T., Hinkel, H., Maedl, A., Hermenau, K., Hecker, T., Schauer, M., ... Lancaster, P. (2013). Sexual and gender-based violence in the Kivu provinces of the Democratic Republic of Congo: Insights from former combatants. Washington, DC: The World Bank. http://www.logicawb.org/PDFs/LOGiCA_SGBV_DRC_Kivu.pdf 
Elbert, T., Rockstroh, B., Kolassa, I.-T., Schauer, M., \& Neuner, F. (2006). The influence of organized violence and terror on brain and mind-a coconstructive perspective. In P. Baltes, P. Reuter-Lorenz, \& F. Rösler (Eds.), Lifespan development and the brain: The perspective of biocultural coconstructivism. Cambridge, England: Cambridge University Press.

Elbert, T., \& Schauer, M. (2002). Burnt into memory. Nature, 419, 883. doi: $10.1038 / 419883 a$

Elbert, T., Weierstall, R., \& Schauer, M. (2010). Fascination violence: On mind and brain of man hunters. European Archives of Psychiatry and Clinical Neuroscience, 260, 100-105. doi:10.1007/s00406-010-0144-8

Ertl, V., Pfeiffer, A., Saile, R., Schauer, E., Elbert, T., \& Neuner, F. (2010). Validation of a mental health assessment in an African conflict population. Psychological Assessment, 22, 318-324. doi:10.1037/a0018810

Fazel, M., Wheeler, J., \& Danesh, J. (2005). Prevalence of serious mental disorder in 7000 refugees resettled in western countries: A systematic review. The Lancet, 365, 1309-1314. doi:10.1016/S0140-6736(05)61027-6

Foa, E. B., Riggs, D. S., Dancu, C. V., \& Rothbaum, B. O. (1993). Reliability and validity of a brief instrument for assessing post-traumatic stress disorder. Journal of Traumatic Stress, 6, 459-473. doi:10.1007/BF00974317

Foa, E. B., \& Tolin, D. F. (2000). Comparison of the PTSD Symptom Scaleinterview version and the Clinician-Administered PTSD Scale. Journal of Traumatic Stress, 13, 181-191. doi:10.1023/A:1007781909213

Hebb, D. O. (1949). The organization of behaviour. New York, NY: Wiley.

Hecker, T., Hermenau, K., Crombach, A., \& Elbert, T. (2015). Treating traumatized offenders and veterans by means of narrative exposure therapy. Frontiers in Psychiatry, 6, 80. doi:10.3389/fpsyt.2015.00080

Hecker, T., Hermenau, K., Maedl, A., Elbert, T., \& Schauer, M. (2012). Appetitive aggression in former combatants-Derived from the ongoing conflict in DR Congo. International Journal of Law and Psychiatry, 35, 244-249. doi:10.1016/j.ijlp.2012.02.016

Hecker, T., Hermenau, K., Maedl, A., Hinkel, H., Schauer, M., \& Elbert, T. (2013). Does perpetrating violence damage mental health? Differences between forcibly recruited and voluntary combatants in DR Congo. Journal of Traumatic Stress, 26, 142-148. doi:10.1002/jts.21770

Hecker, T., Hermenau, K., Maedl, A., Schauer, M., \& Elbert, T. (2013). Aggression inoculates against PTSD symptom severity-insights from armed groups in the eastern DR Congo. European Journal of Psychotraumatology, 4, 20070. doi:10.3402/ejpt.v4i0.20070

Hermenau, K., Hecker, T., Maedl, A., Schauer, M., \& Elbert, T. (2013). Growing up in armed groups: Trauma and aggression among child soldiers in DR Congo. European Journal of Psychotraumatology, 4, 21408. doi:10.3402/ejpt.v4i0.21408

Hermenau, K., Hecker, T., Ruf, M., Schauer, E., Elbert, T., \& Schauer, M. (2011). Childhood adversity, mental ill-health and aggressive behavior in an African orphanage: Changes in response to trauma-focused therapy and the implementation of a new instructional system. Child and Adolescent Psychiatry and Mental Health, 5(1), 29. doi:10.1186/1753-2000-5-29

Hermenau, K., Hecker, T., Schaal, S., Maedl, A., \& Elbert, T. (2013). Addressing post-traumatic stress and aggression by means of narrative exposure- a randomized controlled trial with ex-combatants in the eastern DRC. Journal for Maltreatment, Aggression and Trauma, 22, 916-934. doi:10.1080/10926771.2013.824057

Hu, L., \& Bentler, P. M. (1999). Cutoff criteria for fit indexes in covariance structure analysis: Conventional versus new alternatives. Structural Equation Modeling, 6, 1-55. doi:10.1080/10705519909540118

Kolassa, I.-T., \& Elbert, T. (2007). Structural and functional neuroplasticity in relation to traumatic stress. Current Directions in
Psychological Science, 16, 321-325. doi:10.1111/j.1467-8721.2007. 00529.x

Kolassa, I.-T., Ertl, V., Eckart, C., Kolassa, S., Onyut, L. P., \& Elbert, T. (2010). Spontaneous remission from PTSD depends on the number of traumatic event types experienced. Psychological Trauma: Theory, Research, Practice, and Policy, 2, 169-174. doi:10.1037/a0019362

Kolassa, I.-T., Illek, S., Wilker, S., Karabatsiakis, A., \& Elbert, T. (2015). Neurobiological findings in post-traumatic stress disorder. In U. Schnyder \& M. Cloitre (Eds.), Evidence based treatments for trauma-related psychological disorders (pp. 63-86.). Heidelberg, Germany: Springer. doi: 10.1007/9783-319-07109-1

Leeies, M., Pagura, J., Sareen, J., \& Bolton, J. M. (2010). The use of alcohol and drugs to self-medicate symptoms of posttraumatic stress disorder. Depression and Anxiety, 27, 731-736. doi:10.1002/da.20677

MacDonald, G., \& Leary, M. R. (2005). Why does social exclusion hurt? The relationship between social and physical pain. Psychological Bulletin, 131, 202-223. doi:10.1037/0033-2909.131.2.202

Marsee, M. A. (2008). Reactive aggression and posttraumatic stress in adolescents affected by Hurricane Katrina. Journal of Clinical Child and Adolescent Psychology, 37, 519-529. doi:10.1080/15374410802148152

Moran, J., Weierstall, R., \& Elbert, T. (2014). Differences in brain circuitry for appetitive and reactive aggression as revealed by realistic auditory scripts. Frontiers in Behavioral Neuroscience, 8, 426. doi:10.3389/fnbeh.2014.00425

Neuner, F., Schauer, M., Karunakara, U., Klaschik, C., Robert, C., \& Elbert, T. (2004). Psychological trauma and evidence for enhanced vulnerability for posttraumatic stress disorder through previous trauma among West Nile refugees. BMC Psychiatry, 4, 34. doi:10.1186/1471-244X-4-34

Neuner, F., Schauer, M., Klaschik, C., Karunakara, U., \& Elbert, T. (2004). A comparison of narrative exposure therapy, supportive counseling, and psychoeducation for treating posttraumatic stress disorder in an African refugee settlement. Journal of Consulting and Clinical Psychology, 72, 579587. doi:10.1037/0022-006X.72.4.579

Russell, J. A. (1980). A circumplex model of affect. Journal of Personality and Social Psychology, 39, 1161-1178. doi:10.1037/h0077714

Saile, R., Ertl, V., Neuner, F., \& Catani, C. (2014). Does war contribute to family violence against children? Findings from a two-generational multiinformant study in Northern Uganda. Child Abuse and Neglect, 38, 135-146. doi:10.1016/j.chiabu.2013.10.007

Schalinski, I., Elbert, T., \& Schauer, M. (2011). Female dissociative responding to extreme sexual violence in a chronic crisis setting: The case of Eastern Congo. Journal of Traumatic Stress, 24, 235-238. doi:10.1002/jts.20631

Schauer, M., Neuner, F., Karunakara, U., Klaschik, C., Robert, C., \& Elbert, T. (2003). PTSD and the "building block" effect of psychological trauma among West Nile Africans. ESTSS Bulletin, 10(2), 5-6.

Schumacker, R. E., \& Lomax, R. G. (2010). A beginner's guide to structural equation modeling (3rd ed.). London, England: Psychology Press, Taylor and Francis Group.

Stevens, J. P. (1984). Outliers and influential data points in regression analysis. Psychological Bulletin, 95, 334. doi:10.1037/0033-2909.95.2.334

Thornberry, T. P., Knight, K. E., \& Lovegrove, P. J. (2012). Does maltreatment beget maltreatment? A systematic review of the intergenerational literature. Trauma, Violence \& Abuse, 13, 135-152. doi:10.1177/1524838012447697

United Nations High Commissioner for Refugees (UNHCR). (2013a). UNHCR Global Trends 2012. Geneva, Switzerland: Author http://www.unhcr.org/cgi-bin/texis/vtx/home/opendocPDFViewer.html? docid $=51$ bacb0f9\&query $=$ global $\% 20$ trends $\% 202012$ 
United Nations High Commissioner for Refugees (UNHCR). (2013b). UNHCR Mid-Year Trends 2013. Geneva, Switzerland: Author. http://www.unhcr.org/cgi-bin/texis/vtx/home/opendocPDFViewer.html? docid $=52$ af08d26\&query $=$ mid $\% 20$ year $\% 20$ trends $\% 202013$

United Nations High Commissioner for Refugees Uganda (2015). Nakivale fact sheet 2015. Mbarara, Uganda: Author. http://www.data.unhcr.org/drc/download.php?id=1048

Vitiello, B., \& Stoff, D. M. (1997). Subtypes of aggression and their relevance to child psychiatry. Journal of the American Academy of Child and Adolescent Psychiatry, 36, 307-315. doi:10.1097/00004583-19970300000008

Weierstall, R., Bueno Castellanos, C. P., Neuner, F., \& Elbert, T. (2013). Relations among appetitive aggression, post-traumatic stress and motives for demobilization: A study in former Colombian combatants. Conflict and Health, 7, 9. doi:10.1186/1752-1505-7-9

Weierstall, R., \& Elbert, T. (2011). The Appetitive Aggression Scaledevelopment of an instrument for the assessment of human's attraction to violence. European Journal of Psychotraumatology, 2, 8430. doi:10.3402/ejpt.v2i0.8430

Weierstall, R., \& Elbert, T. (2012). Formen und klassifikationen menschlicher aggression. In J. Endrass, A. Rossegger, F. Urbaniok, \& B. Borchard (Eds.), Interventionen bei gewaltund sexualstraftätern: Risk-management, meth- oden und konzepte der forensischen therapie (1st ed.). Berlin, Germany: Medizinisch Wissenschaftliche Verlagsgesellschaft.

Weierstall, R., Hinsberger, M., Kaminer, D., Holtzhausen, L., Madikane, S. \& Elbert, T. (2013). Appetitive aggression and adaptation to a violent environment among youth offenders. Peace and Conflict: Journal of Peace Psychology, 19, 138-149. doi:10.1037/a0032489

Weierstall, R., Schaal, S., Schalinski, I., Dusingizemungu, J.-P., \& Elbert, T. (2011). The thrill of being violent as an antidote to posttraumatic stress disorder in Rwandese genocide perpetrators. European Journal of Psychotraumatology, 2, 6345. doi:10.3402/ejpt.v2i0.6345

Weierstall, R., Schalinski, I., Crombach, A., Hecker, T., \& Elbert, T. (2012) When combat prevents PTSD symptoms-results from a survey with former child soldiers in Northern Uganda. BMC Psychiatry, 12, 41. doi:10.1186/1471-244X-12-41

Wilker, S., Pfeiffer, A., Kolassa, S., Koslowski, D., Elbert, T., \& Kolassa, I.-T. (in press). How to quantify exposure to traumatic stressors? Reliability and predictive validity of measures for cumulative trauma exposure in a post-conflict population. European Journal of Psychotraumatology.

World Health Organization. (1992). ICD-10 classification of mental and behavioural disorders: Clinical descriptions and diagnostic guidelines. Geneva, Switzerland: Author. 